\title{
GINA D'MASCAR: A PERFORMANCE DO RIDÍCULO
}

Andressa de Freitas Ribeiro andressa.antropologia@gmail.com Universidade Federal da Bahia (UFBA), Salvador, Bahia, Brasil.

\begin{abstract}
RESUMO
O presente trabalho consiste em uma descrição de dois episódios centrados em uma Drag Queen cujo nome é Gina D' Mascar. Gina D'Mascar é uma personagem extremamente original e que quebra todos os estereótipos da Drag Queen tradicional; possui uma aparência exagerada que beira o ridículo - a maquiagem carregada, o cabelo disforme, o corpo grande e cheio e os dentes pintados dando a aparência de que estão estragados. Gina D' Mascar se apresenta toda quarta-feira em um espaço de sociabilidade LGBTTT denominado Beco dos Artistas localizado na cidade de Salvador-Ba. O Beco sempre foi um lugar povoado de personagens ricos para pensar as temáticas de gênero, corpo e sexualidade, dentre essas personagens está a Drag Queen Gina D’Mascar.
\end{abstract}

PALAVRAS-CHAVE: Drag Queen. Gina D`Mascar. Performatividade de gênero. 


\section{INTRODUÇÃO}

O Beco dos Artistas surge em meados da década de 70 como um espaço de encontro da classe artística e intelectual de Salvador. O Beco era um lugar propício para o encontro entre artistas e intelectuais por se localizar próximo ao Teatro Castro Alves, à escola de teatro da Universidade Federal da Bahia e ao teatro Vila Velha. Com o passar dos anos, através de uma série de transformações, o Beco dos Artistas deixa de ser um espaço voltado para a classe artística e intelectual e se torna um espaço de sociabilidade LGBTTT. Foi nesse período, já quando o Beco passou a ser conhecido como beco dos viados, que realizei o trabalho de campo.

Quando comecei a fazer campo, em 2008, o Beco dos Artistas possuía quatro bares: o Bar Cultural, o Camarim, o Bar de Eduardo e o Green Bar. O Beco funcionava todos os dias à noite, exceto na segunda-feira. Em 18 de Março de 2009, um dos principais bares do Beco - o Camarim - fecha e o Beco fica, então, com apenas três bares - o Bar Cultural, o Bar de Eduardo e o Green Bar. O Beco se localiza na Av. Cerqueira Lima uma viela cuja entrada dá para a avenida principal - a Av. Leovigildo Filgueiras - e o fundo para uma comunidade de moradores evangélicos. Isso dota o Beco de certa invisibilidade; as pessoas que passam pela avenida principal nem sempre se dão conta de que existe um espaço de sociabilidade homossexual ali.

Essa invisibilidade foi fundamental para que o beco se tornasse um ponto de concentração dos mais distintos personagens que transgridem as normas de gênero e sexualidade - gays afeminados, gays másculos, lésbicas masculinas, lésbicas femininas, gays estrangeiros e velhos, gays negros e jovens, bissexuais, travestis e michês. Dentre esses personagens destaca-se a Drag Queen Gina D'Mascar. Gina D' Mascar é uma personagem que quebra todos os estereótipos de uma Drag Queen, ela aposta na construção de uma personagem original que brinca com o exagero - o exagero dos gestos, o exagero da maquiagem, o exagero da voz e do corpo - e se aproxima do ridículo e do marginal.

Gina D'Mascar se apresentava, inicialmente, toda quarta-feira no Bar Camarim. Depois que o Camarim fechou, Gina D'Mascar passou a fazer, durante um período de tempo, shows no Bar Cultural. Neste artigo, descreverei uma apresentação de Gina D'Mascar no Bar Camarim e depois, descreverei o processo de transformação de Aldo $^{1}$ em Gina D'Mascar, que pude acompanhar, já no Bar Cultural. A partir dessas descrições, desses exemplos empíricos, refletirei sobre o potencial questionador e subversivo dessa personagem no que se refere às normas heterossexuais de gênero e sobre a relação que existe entre sua performance do ridículo e a posição social da homossexualidade.

\section{GINA D'MASCAR}

Toda quarta-feira, às 21:30h, acontece o show de Gina D`Mascar no Beco dos Artistas. Ela sai toda glamorosa de dentro do Bar Camarim, com sua taça imensa de cerveja, desfilando pela rua e convidando a todos e todas para assistir ao seu show. Quem representa Gina é um garçom do Camarim, chamado Aldo, que trabalha também com teatro. O espaço onde Gina realiza o show é um espaço amplo, com duas mesas de sinuca. No canto esquerdo da entrada para 
esse espaço fica um palco pequeno onde Gina faz sua apresentação. Na frente do palco, uma série de cadeiras e mesas fica arrumada para a chegada do público. Em frente ao balcão de atendimento, no espaço onde Gina se apresenta, tem um painel de fotos com celebridades, homens e mulheres se beijando, galãs de novela sem camisa, mulheres seminuas.

O show começa com ela interagindo com a platéia, arriscando uns passos de dança. Gina não é uma Drag que preza pela perfeição estética, ela é o contrário disso e beira quase o ridículo. Especificamente, no dia em que assisti ao show, Gina estava com um vestido rosa choque, um punhado de panos cor de abóbora pendurado no pescoço, algo parecido com xale, mas muito mais esdrúxulo. Uma bota preta com salto plataforma, uma maquiagem bem extravagante. Uma sobrancelha bem preta e bem grossa, uma peruca loura, com cabelos nos ombros e muito despenteados, uma boca meio cinza brilhosa, um rosto bem branco com as bochechas rosa e alguns dentes pintados de preto, o que dava a impressão de ela estar sem alguns dentes.

O cenário do seu show era um banquinho que ela usava para descansar quando fazia muito esforço físico, uma taça de cerveja imensa e uma boneca que ficava em cima da caixa de som e que imitava seus traços, parecia uma Gina em miniatura. $O$ rosto redondo e o mesmo tipo de maquiagem causavam um efeito de muita semelhança entre a boneca e Gina. Ela sempre usava a boneca em um ou outro momento do show. O show se constituía por dublagens de um estilo de música não tão comum em shows de transformistas ou mesmo Drag Queens, ela dublou muita música nacional como, por exemplo, Fafá de Belém e Alcione. As músicas, em sua maioria, falavam de um amor perdido, de ciúmes, de encontros e desencontros.

Ela demonstrava uma espontaneidade fora do comum, é como se o palco fosse sua casa, a graça do seu show estava na sua simplicidade. Em nenhum momento, ela fez movimentos bruscos, ou, precisou apelar para malabarismos corporais para conseguir chamar a atenção da platéia. Teve um momento do show que me chamou muita atenção; quando ela leu uma carta escrita pela Igreja Universal do Reino de Deus, mandada por alguém do público. A carta tinha um conteúdo que se referia a como as pessoas deviam conviver com sua sexualidade, qual a melhor posição de fazer sexo e o que não deveria ser feito na relação sexual.

Ao mesmo tempo em que ela lia a carta, ela ia ironizando o seu conteúdo, fazendo comentários, mudando as frases com uma maestria e um humor muito refinados. A carta começou dizendo que a melhor posição para uma relação sexual é o homem deitado e a mulher sentada, sem que os corpos se encostem, eles devem estar vestidos, embora os órgãos sexuais devam ficar descobertos. 0 sexo oral não é permitido. A carta afirma que essas são duas regiões responsáveis por funções excretoras e, por isso, muito sujas, às quais a boca e a língua não devem ter contato. A boca é feita para comer e a língua para sentir os sabores. É bom lembrar que, o tempo todo, ela está parodiando essas frases.

A relação sexual, segundo a carta, não deve gerar prazer, sua função é apenas a reprodução e se, por acaso, os participantes da relação sentirem prazer, devem se punir, açoitando-se com varas de bambu, pois se não, se o prazer for sentido sem penitência, o destino desses indivíduos será o inferno. Gina termina 
falando que ou o inferno não vai caber tanta gente ou vai faltar vara de bambu no mundo.

Gina contestava, a tempo todo, a visão da Igreja Universal. É interessante, porque o Beco é um lugar que propicia, em cada canto do espaço, nas paredes e nos banheiros, nas músicas e clipes que passam na televisão, uma atmosfera regida por um sentido sexual. Então, uma carta da Igreja Universal do Reino de Deus, dizendo como se deve fazer sexo ou não, afirmando que o sexo não deve ser usado para sentir prazer e, sim, para procriação, o que é impossível em relações homossexuais, sendo lida e parodiada ali, no Beco dos Artistas, um espaço de sociabilidade homossexual, torna explícito o contraste de perspectivas entre dois segmentos sociais.

Aquele foi um momento representativo de dois mundos de valores muito distintos. Uma carta que não concebe a existência social-sexual de seres que estavam ali, naquele espaço, ouvindo e sentindo o peso de um setor da sociedade que os repudia e, ao mesmo tempo, estes mesmos seres estavam brincando, rindo, superando aquelas frases através da paródia e validando sua existência e legitimidade através do humor.

Depois que ela leu a carta, ela começou a fazer as dublagens e, no intervalo de uma dublagem e outra, ela interagia com a platéia e a platéia interagia com ela. A platéia gritava: puta, vadia. E ela fazia uma expressão de estar se sentindo super elogiada. Quando a platéia gritava: gostosa, linda, ela falava: deixa de ser mentiroso, quem é esse viado mentiroso aí da platéia? Durante o show houve duas participações especiais. Mas, as duas tinham estilos muito diferentes do de Gina, prezavam pelo glamour e pelos malabarismos corporais em suas dublagens, colocavam-se na posição de estrelas, no centro do palco, enquanto Gina tinha uma performance mais circular, ocupando todo o espaço do palco.

Essas duas participantes fizeram um total de três apresentações, cada uma delas fez uma apresentação solo e, depois, elas fizeram um dueto. As apresentações consistiam basicamente em dublagens. Elas apresentavam, conversavam um pouco com Gina e saiam. O show foi até as 00:30h, como era o previsto.

Valeria aqui fazer uma reflexão sobre a Drag Queen e seu papel de paródia do gênero baseada nos argumentos de Guacira Lopes Louro (2004) e Judith Butler $(2003 ; 2002)$.

O tempo todo, na nossa sociedade, os corpos são marcados com códigos, sinais, adereços que, além de ter expressão simbólica, terão efeitos sociais e materiais. O corpo da mulher e do homem é o tempo todo marcado para que possa entrar no mundo da cultura de uma forma coerente e inteligível. Aquilo que é criado e construído ganha um sentido de autenticidade e originalidade que Ihe parece próprio. $O$ que é construído se cristaliza a tal ponto de parecer natural, inerente e próprio à natureza humana. O gênero, por sua vez, é uma dessas esferas que, por meio de sinais e códigos que marcam o corpo, se cristalizam ao ponto de parecer natural. A paródia é, nesse sentido, um forte instrumento de contestação e desestabilização dessa pressuposta autenticidade. "É exatamente aí que a figura da Drag permite pensar sobre os gêneros e a sexualidade, permite questionar a essência ou autenticidade dessas dimensões e refletir sobre seu caráter construído" (LOURO, 2004, p. 85). 
"Sua figura estranha e insólita ajuda a lembrar que as formas como nos apresentamos como sujeitos de gênero e de sexualidade são, sempre, formas inventadas e sancionadas pelas circunstâncias culturais em que vivemos. Os corpos considerados normais e comuns são, também, produzidos através de uma série de artefatos, acessórios, gestos, e atitudes que uma sociedade arbitrariamente estabeleceu como adequados e legítimos. Nós também nos valemos de artifício e de signos para nos apresentarmos, para dizer quem somos e dizer quem são os outros" (LOURO, 2004, p. 86).

Isso mostra o quanto o gênero é uma categoria construída e como a Drag ao parodiar esse gênero, desvela seu caráter construído. Além disso, a figura da Drag demonstra a ineficácia do sistema sexo-gênero, quer dizer, "de um conjunto de arranjos através dos quais uma sociedade intenta transformar a sexualidade biológica em produtos da atividade humana" (RUBIN, 1993, p. 2). Ao imitar e exagerar os traços do feminino, a Drag desvela os imperativos culturais que nenhum indivíduo elege, mas é obrigado desde sua mais tenra existência a negociar.

O que se põe em cena na Drag é, sem dúvida, o signo do gênero, um signo que não é idêntico ao corpo que representa, mas que não pode ser interpretado sem esse corpo. O signo entendido como um imperativo de gênero - a menina - não se interpreta como uma atribuição mas, sim, como uma ordem e, como tal, produz suas próprias insubordinações. A conformidade hiperbólica à ordem pode revelar o caráter hiperbólico da própria norma, e mais, pode converter o signo cultural que torna legível o imperativo cultural. Posto que as normas heterossexuais de gênero produzem ideais inacessíveis, podemos dizer que a heterossexualidade opera mediante a produção regulada de versões hiperbólicas do homem e da mulher. Em sua maioria, trata-se de representações que nenhum de nós elege, mas, com as quais estamos obrigados a negociar. Escrevo obrigados a negociar porque o caráter obrigatório dessas normas nem sempre as faz eficazes. Estas normas são sempre assediadas por sua própria ineficácia, daí que se repetem, de maneira angustiante, os esforços para estabelecer e incrementar sua jurisdição (BUTLER, 2002, p. 73).

A fala de Butler (2002) deixa claro como o gênero é um imperativo da cultura e como a figura da Drag, ao assumir esse caráter hiperbólico, revela o caráter mesmo hiperbólico dos próprios imperativos culturais e, além do mais, explicita seu caráter ineficaz. O gênero se revela, então, como um tipo ideal impossível de ser alcançado de uma forma fidedigna. Isso se revela não só na Drag Queen, quando parodia o gênero ao assumir uma postura, um comportamento e uma forma de se vestir que não são "adequados" ao seu sexo biológico, mas, também, nas diferentes formas que os diferentes indivíduos negociam com as categorias de gênero nas suas vidas cotidianas. Um homem nunca é cem por cento masculino e uma mulher nunca é cem por cento feminina. As categorias de gênero são, nesse sentido, categorias aproximativas.

\section{A TRANSFORMAÇÃO DE ALDO EM GINA D’MASCAR E O RIDÍCULO.}

O outro episódio que descreverei é o processo de transformação de Aldo em Gina D'Mascar que pude acompanhar no Bar Cultural. No dia 24/03/2010, uma quarta-feira, fui assistir ao show de Gina no Beco. Era mês de março, o tempo 
estava chuvoso e isso fez com que o movimento diminuísse. Entrei no Bar Cultural e vi que o bar estava vazio. Então, fui cumprimentar Eduardo ${ }^{2}$ que já tinha encontrado mais cedo e avisado que iria hoje ao Beco, ver o show de Gina. Ele me convidou imediatamente para entrar no camarim de Aldo, para ver a transformação de Aldo em Gina. Entrei e percebi que Aldo ficou meio desconcertado de início. É como se, de alguma forma, eu estivesse invadindo um espaço íntimo seu. Provavelmente, ele achou que eu fosse fazer uma entrevista e falou: pode falar, pode começar as perguntas. No entanto, embora ele tenha dito para eu falar, em nenhum momento ele parou seu trabalho. Continuou de frente para um espelho, uma penteadeira feita de improviso, em um quarto minúsculo, onde era seu espaço de transformação. O quarto era bem pequeno, as paredes estavam descascando, era tudo muito simples e sem nenhuma sofisticação. Aldo ficava sentado numa cadeira de plástico, de frente para um espelho pendurado e uma penteadeira improvisada com uma mesa velha. Acompanhei esse processo de transformação desde o início.

Como havia dito, Aldo continuou seu trabalho normalmente. De início apresentou certa estranheza com a minha presença, mas, depois, foi-se acostumando. Não estava ali com intuito de fazer uma entrevista. Pensei que ali não era o momento adequado de entrevistá-lo. Ele estava se transformando, um trabalho que exige muita atenção, um trabalho pormenorizado e cheio de detalhes. No fim do processo, você se dá conta de que ele é o produto modificado da sua própria capacidade de intervenção artística. Aldo, naquele momento, era, ao mesmo tempo, o artista e a obra de arte. Se, por ventura, o artista - pintor, escultor, músico - se modifica indiretamente ao criar uma obra que tenha realidade material própria, exterior a si mesmo, Aldo como um transformista, modifica a si mesmo com o desenrolar da sua própria capacidade artística.

Fiquei, em alguns momentos, bastante em silêncio, só observando e, ao mesmo tempo, admirando. Para mim, mais importante ali, não era uma compreensão racional através de perguntas, mas uma compreensão corpórea que se deu através da percepção e do aguçamento dos sentidos por tudo aquilo que os estímulos sensoriais - visual, auditivo, olfativo, tato - me proporcionavam.

Quando entrei, Aldo estava sentando. Aldo é um homem grande. Estava sentado na cadeira e parecia uma espécie de múmia, apesar de ter uma boa movimentação. Aldo estava todo enrolado em meias-calças. Vestia uma meia calça nas pernas, outra que cobria todo seu tronco. Além disso, outras meias calças, em forma de faixas, amarradas na cintura. É realmente uma estrutura muito difícil de descrever, parecia um tipo de armação e era essa armação que, mais tarde, iria sustentar seu corpo falso. Aquele corpo com todas aquelas faixas parecia uma espécie de geringonça. Tinha uma meia-calça feita de faixa que passava pelo pescoço, trançava ao peito e fechava na cintura. Perguntei a Aldo sobre aquela estrutura e ele disse ter inventado tudo. No entanto, disse que, no início, era algo muito mais amador, que ele foi aperfeiçoando com o decorrer dos anos e das apresentações.

Aldo começou a se maquiar. Do seu lado, havia um copo de cerveja, ele bebia e se maquiava. Começou por um pó que deixou sua face mais branca, depois colocou outro pó na bochecha, no queixo, na testa, que deixou seu rosto 
com manchas vermelhas. Depois começou a espalhar esse pó e, então, seu rosto ganhou uma coloração mais uniforme, colocou um cílio postiço e passou um batom bem vermelho na boca. O batom foi passado de uma forma que aumentou sua boca, deixou-a mais volumosa, uma boca grande. Depois Aldo/Gina pegou purpurina e passou por cima da sua Boca. Aldo, nesse momento, já não era a mesma pessoa, já estava se transformando em Gina D'Mascar. Seu rosto começou a mudar de feição, a sobrancelha ficou diferente, a boca ganhou outro formato, ali já não era a mesma pessoa com quem eu iniciei a conversa anteriormente.

Gina, o personagem que começa a despontar através do rosto e do corpo de Aldo, não era, também, um exemplo de beleza. Gina não representava o belo, ao contrário, seu intuito era parodiar o próprio belo através do cômico. Diferente das travestis e de algumas transformistas que se aproximam de uma feminilidade ligada a um ideal de beleza e se esforçam para construir, através dos seus corpos, este ideal, Gina, por outro lado, se desprende desse ideal padronizado de beleza e se aproxima da comédia, do ridículo e do cômico. Gina ia-se transformando e aquelas sobrancelhas grossas, aquela boca feita de batom tão grossa que parecia borrada, embora o traçado fosse muito bem feito, ia aproximando Aldo, cada vez mais, de uma aparência esdrúxula.

Nesse meio tempo, Eduardo entrou no quarto-cubículo, para apressar Aldo/Gina. Disse que já estava tarde e que as pessoas estavam ansiosas. $\mathrm{O}$ show estava marcado para começar às 21:00h, no entanto, já era por volta de $22 \mathrm{~h} 00 \mathrm{~min}$ e Gina ainda estava se aprontando. Conversando com Aldo/Gina, toquei no assunto de que considerava sua performance diferente da de outras transformistas e drags. Aldo/Gina, então, respondeu que, antes de fazer Gina, Aldo já tinha uma formação em teatro e isso lhe trouxe uma postura de palco muito particular. Além disso, Aldo/Gina disse que uma das primeiras coisas que se aprende no teatro é não ter medo do ridículo, pois, se existe o medo do ridículo, dificilmente alguém terá coragem de subir em um palco e de se expor. Afirmou, logo em seguida, que essa era a grande sacada de Gina - explorar o ridículo, expor o ridículo ao ponto dele deixar de ser ridículo ${ }^{3}$.

É possível estabelecer aqui uma relação entre a performance de Gina e a própria condição do homossexual, como o homossexual é muitas vezes ridicularizado, e como o homossexual é colocado na posição do ridículo em nossa sociedade. Talvez fosse interessante pensar o ridículo aqui. $\mathrm{O}$ ridículo me parece aquilo mesmo que não pode ser mostrado. Além do mais, me parece que o ridículo é algo que todo ser humano já experimentou - a sensação do ridículo. Esse ridículo é algo que gera certo desencaixe, parece que é algo que está fora de lugar; que gera uma espécie de desarranjo na cadeia significante, no senso de normalidade. É algo que, por isso, embora tenha um tom cômico, também possui um caráter de ameaça, na medida em que coloca em cheque o sentido de ordem e de normalidade da situação. Sentido este que todo ser humano necessita para ordenar o caráter caótico da experiência vivida. O cômico, por vezes, parece ser uma tentativa mesmo de lidar com esse caráter de ameaça que emerge do ridículo. É preciso tornar cômico aquilo que me causa medo, ou melhor, aquilo que me causa medo, tornando-o cômico, pode deixar de ser ameaçador. O cômico funciona como uma espécie de mecanismo embotador do medo, ou o embotamento daquele conteúdo que existe em mim, mas, com o qual, eu tenho medo de me deparar, isso gera o cômico e, por vezes, o ridículo. Assim, o ridículo 
é algo que diz muito sobre mim, falando de uma forma mais ampla, o ridículo social é algo que diz muito sobre esse social e que, por vezes, faz parte da sua própria constituição. O ridículo é aquilo que existe e que é real, mas que é, ao mesmo tempo, escondido e negado e, por isso, quando emerge, ganha o caráter de irrealidade, de algo fora do lugar.

Essa irrealidade e essa sensação de algo fora do lugar são, no entanto, um falseamento da realidade, uma ilusão criada pelos sujeitos sociais para esconder de si mesmos o conteúdo daquilo que eles ridicularizam. A homossexualidade, nesse sentido, na medida em que ocupa a posição do ridículo social, pode ser algo que diz muito sobre esse mesmo social. Em uma sociedade construída sob o ideal de família, em uma sociedade que se organiza através de vínculos heterossexuais, a homossexualidade é, em si mesma, uma ameaça (BUTLER, $2003,2008)$. No entanto, é sabido que a própria heterossexualidade é uma construção e que o desejo homossexual, ao invés de ser algo bizarro e esdrúxulo, é algo que está presente como realidade no corpo social e na subjetividade dos indivíduos (HALPERIN, 2004; PULET, 2005). Essa presença insidiosa e afamada da homossexualidade é que a torna ridícula. É seu caráter mesmo de realidade, é seu caráter mesmo constitutivo da sociedade, é a sua inevitável presença no social e nas subjetividades que a torna objeto de tanto temor e, por isso mesmo, alvo do ridículo. Daquilo com o que ainda não sabemos lidar em nós mesmos e nos outros. Todo homossexual tem que, por isso, enfrentar, cotidianamente, o peso do ridículo. Esse ridículo que provém de um ethos social é, ao mesmo tempo, internalizado pelo indivíduo. Assim, além de enfrentar a ridicularização que vem do outro, o indivíduo que se depara com seu desejo homossexual tem que enfrentar o senso de ridículo que, muitas vezes, por consequência de ser um ser social, ele internalizou na sua própria subjetividade.

O personagem de Gina é, por isso, muito ilustrativo para pensar a homossexualidade, o Beco e as pessoas que estão ali e fazem parte daquele espetáculo. Gina expõe o ridículo e o coloca em pauta. Nesse sentido, ela se comunica com a maioria das pessoas que estão ali e que vivem o "ridículo", vivem a sina de terem sido colocadas no lugar/posição do ridículo na nossa sociedade. Por outro lado, ao expor o ridículo ao ponto de torná-lo aceitável e até belo em sua expressão de autenticidade; ao vencer o medo de se expor e de expor esse ridículo, Gina lança mão de uma nova possibilidade, da possibilidade da existência do ridículo, da exteriorização do ridículo e da visibilidade do ridículo, ao ponto dele perder seu caráter de ridículo, pois o ridículo só se sustenta diante da sua invisibilidade, como algo incomum, conseqüência da sua própria repressão.

Além disso, quando Gina incorpora o ridículo, de alguma forma ela está sendo cúmplice daqueles indivíduos ali presentes, de alguma forma aqueles indivíduos se sentem identificados com ela, de alguma forma é a comédia da própria vida daqueles indivíduos que está sendo ali representada e parodiada ${ }^{4}$. Gina é a representação do ridículo da posição que a homossexualidade ocupa na nossa sociedade e é, ao mesmo tempo, a representação da superação dessa condição. O ridículo toma o palco e ganha expressividade, o ridículo se expõe e perde seu caráter de ridículo.

Ao terminar a maquiagem, Gina/Aldo pegou uma bola cheia de água e se contorcendo toda, numa espécie de malabarismo corporal, Gina conseguiu enfiar 
aquela bola imensa dentro daquele emaranhando de meia-calça enroladas pelo seu corpo, para fazer os seios. Gritou Eduardo e Eduardo chegou com outra bexiga cheia de água. Aldo/Gina falou que a bexiga estava menor do que a outra que ele tinha acabado de colocar. Eduardo falou: não tem problema, vai assim mesmo. Gina/Aldo disse: não, vai ficar desproporcional. Mas, Eduardo falou que não tinha jeito de colocar mais água e, então, Aldo/Gina aceitou. Gina, com menos dificuldade do que a primeira bola que estava mais cheia, colocou o outro seio. Eram seios imensos, mas, um ficou maior que o outro. Logo depois, Aldo/Gina colocou um vestido branco, um sapato vermelho com um salto altíssimo e, por fim, pôs a sua peruca. Dentro daquele emaranhado de panos, havia uma almofada na região de sua barriga que dava a aparência de Gina ser uma mulher gorda e forte. A peruca de Gina era loura, mas o cabelo era todo bagunçado, parecia um emaranhado de fios disformes, era curto, ia até abaixo da orelha aproximadamente e apontava para várias direções, para cima e para baixo. Agora, Aldo já havia se transformado em Gina D'Mascar. Depois que Gina ficou pronta, tendo passado por todo esse processo de transformação, eu resolvi me retirar para que ela ficasse à vontade. Quando saí, me sentei em uma mesa para assistir ao show e percebi que o bar já não estava tão vazio.

\section{CONSIDERAÇÕES FINAIS}

Para entender a experiência de Gina D'Mascar no Beco dos Artistas e retirar desta experiência todo o seu potencial subversivo é necessário compreender que, culturalmente, todos os corpos são marcados por códigos, sinais e adereços com intuito de produzir uma pressuposta coerência entre o sexo/gênero/desejo e prática sexual Butler (2008). Essa coerência é exigida para que esses corpos entrem no mundo social como corpos normais.

No entanto, é preciso frisar, que mesmo os corpos considerados normais, quer dizer, mesmo os corpos que encerram uma suposta coerência entre sexo e gênero são corpos produzidos pelo que Teresa de Lauretis (1989) chama de tecnologias do gênero. Essa tecnologia age no sentido de produzir corpos através da mobilização de uma série de artefatos para que o corpo de uma mulher se apresente como feminino e o corpo de um homem como masculino. Recorrer a esses artefatos para produzir um corpo coerente e normal desvela que o gênero não é uma conseqüência natural do sexo biológico, mas, é sim, como afirma Butler (2002), uma injunção normativa com a qual todo ser está obrigado a negociar desde a sua mais tenra infância.

A paródia de gênero efetuada por Gina D'Mascar contém um forte poder de desestabilização e contestação dessa pressuposta autenticidade. Além de demonstrar a ineficácia do sistema sexo-gênero - na medida em que produz o gênero feminino em um corpo masculino -, ela também demonstra os imperativos culturais que agem sobre um corpo gendrado. Quando Gina D'Mascar hiperboliza os atributos femininos, ao ponto de beirar o ridículo, ela está evidenciando o caráter mesmo hiperbólico das normas de gênero, na medida em que essas normas produzem ideais de homem e de mulher inacessíveis e sempre aproximativos.

Concomitante a performance de gênero, Gina D'Mascar também se apresenta como uma paródia do ridículo, ou melhor, da posição do ridículo ${ }^{5}$. 0 
exagero da maquiagem e das vestimentas, os dentes pintados de preto que aparentam ausência de dentes, os gestos hiperbólicos, tudo isso cria uma aparência esdrúxula, uma aparência disforme, de um personagem que não se encaixa em uma ordem e de difícil classificação. O ridículo é essa experiência mesmo que gera certo desencaixe, que parece estar fora de lugar e que gera certo desarranjo na cadeia significante e no sentido de normalidade.

A performance de Gina D'Mascar é dotada de certa comicidade, de certo humor. $\mathrm{O}$ cômico é uma conseqüência da emergência mesmo do ridículo, da sua encenação. Tudo que é considerado ridículo, antes de emergir como tal, antes possui como característica a invisibilidade. O ridículo, em geral, é invisibilizado, é aquilo que não se vê, é aquilo que não se mostra, do que não se fala, daí que a sua externalização implica na conformação de um sentido incomum e anormal, portanto, ridículo.

Rubin (1993) ao falar sobre heterossexualidade compulsória, que é a tendência de toda e qualquer sociedade a impelir os indivíduos a adotarem arranjos afetivos heterossexuais, já afirmava que o tabu da homossexualidade é anterior mesmo ao tabu do incesto. Butler (2008) ao desenvolver o conceito de heteronormatividade como um conjunto de normas que não só privilegiam a sexualidade heterossexual, mas oprime outras expressões de sexualidade, também, já anunciava a tendência da heterenorma de produzir seres abjetos seres sem lugar e sem inteligibilidade na sociedade mais ampla. Mesmo Foucault (2007) quando caracteriza a sexualidade como um dispositivo de saber e poder que incide sobre os corpos e que cria uma espécie a parte, com uma essência própria - o homossexual - já atentava para a formação de toda uma gentália, de toda uma população de travestidos, transviados e homossexuais que seriam posicionados a margem das sociedades ocidentais.

Tendo em vista que o público que frequenta o Beco dos Artistas - e, consequentemente, o público de Gina D'Mascar - é formado por indivíduos que não correspondem a pressuposta coerência entre sexo/gênero/ desejo e prática sexual (BUTLER, 2008), por indivíduos que transgridem as normas de gênero e sexualidade - gays, lésbicas, travestis, michês - e tendo em vista que o show de Gina D’Mascar é um diálogo cômico com a vida e a experiência dessas pessoas, podemos, então, inferir daí que o ridículo que Gina D’Mascar parodia no seu corpo, nos seus gestos, na sua performance é mesmo a posição do ridículo que esses seres ocupam socialmente. Parodiar o ridículo é, no entanto, afirmar a sua possibilidade de existência e, ao mesmo tempo, legitimá-lo através do riso. Essa é a grande subversão provocada por Gina D’Mascar. 


\title{
GINA D'MASCAR: PERFORMANCE OF THE RIDICULOUS
}

\begin{abstract}
This paper consists of a description of two episodes centered on a Drag Queen whose name is Gina D'Mascar. Gina D'Mascar is a very original character and breaks all stereotypes of traditional Drag Queen; has an exaggerated look that borders on the ridiculous - a heavy makeup, shapeless hair, large and full body and painted teeth giving the appearance that they are spoiled. Gina D'Mascar does shows every Wednesday in a space of sociability LGBTTT called Beco dos Artistas in the city of Salvador-Bahia. Beco dos Artistas has always been a place inhabited by characters who question the norms of gender and sexuality, among these characters is a Drag Queen Gina D`Mascar.
\end{abstract}

KEYWORDS: Drag Queen. Gina D’Mascar. Gender performance. 
1 Ator, transformista e performer.

2 Naquele momento, Eduardo estava responsável pelo Bar Cultural.

3 É interessante como essa fala de Aldo me lembrou da proposta da Teoria Queer. O termo queer, que significa estranho, era inicialmente um termo pejorativo, um insulto que se referia aos homossexuais afeminados. $O$ que a teoria queer propõe é ressignificar esse termo, é utilizá-lo e assumi-lo ao ponto de inverter seu sentido (GAMSON, 2002). É utilizar a linguagem contra ela mesma na tentativa de, ao parodiar o termo, esvaziá-lo do seu sentido negativo. A relação de Aldo com o ridículo caminha, também, nesse sentido. Ele se propõe a assumir essa posição, ao ponto dessa posição perder seu caráter de negatividade.

4 Boa parte do show de Gina é composta por pessoas da platéia que vão até a frente do palco para falar de suas vidas. É um show interativo, em que a platéia é um dos protagonistas. Gina chama as pessoas na frente e desenvolve o show, sob improviso, através das falas e dos depoimentos do público.

5 É importante frisar que o termo ridículo foi utilizado pelo próprio Aldo ao falar sobre sua personagem.

\section{REFERÊNCIAS}

BUTLER, Judith. O parentesco é sempre tido como heterossexual? Cadernos Pagu, Unicamp, n. 21, 2003, p.219-260.

BUTLER, Judith. Problemas de Gênero. Rio de Janeiro: Civilização Brasileira, 2008.

BUTLER, Judith. Criticamente Subversiva. In: JIMÉNEZ, Rafael M. Mérida. Sexualidades transgresoras. Una antología de estudios queer. Barcelona: Icária editorial, 2002, p. 55 a 81.

FOUCAULT, Michel. História da sexualidade I - a vontade de saber. Rio de janeiro: Graal, 2007.

GAMSON, Joshua. Devem autodestruirse los movimentos identitários? Um extraño dilema. In: JIMÉNEZ, Rafael M. Mérida (ed.). Sexualidades transgressoras: Uma antologia de estudos queer. Barcelona: Icaria, 2002, p.141172.

HALPERIN, David. La política queer de Michel Foucault. In: HALPERI, David. San Foucault - para uma hagiografia gay. Córdoba: Ediciones Literales, 2004, p. 35145. 
LAURETIS, Teresa de. La tecnologia del gênero. In: Technologies of Gender. Essays on Theory, Film and Ficton. London, Macmillan Press, 1989, p. 7-34.

LOURO, Guacira Lopes. Um corpo estranho: ensaios sobre a sexualidade e teoria queer. Belo Horizonte: Autêntica, 2004.

RUBIN, Gayle. O tráfico de mulheres: notas sobre a "economia política" do sexo. Recife: SOS, CORPO, 1993.

Recebido: 09 de setembro de 2014.

Aprovado: 12 de novembro de 2016.

Como citar:

RIBEIRO, Andressa de Freitas. Gina D’Mascar: a performance do ridículo. Cad. Gên. Tecnol., Curitiba, v. 9, n. 34, p. 72-83, jul./dez. 2016.

Correspondência:

Andressa de Freitas Ribeiro

Rua Augusto Viana, s/n - Palácio da Reitoria , Canela , 40110-909, Salvador.

Direito autoral: Este artigo está licenciado sob os termos da Licença Creative Commons Atribuição 4.0 Internacional.

(c) (i) 